
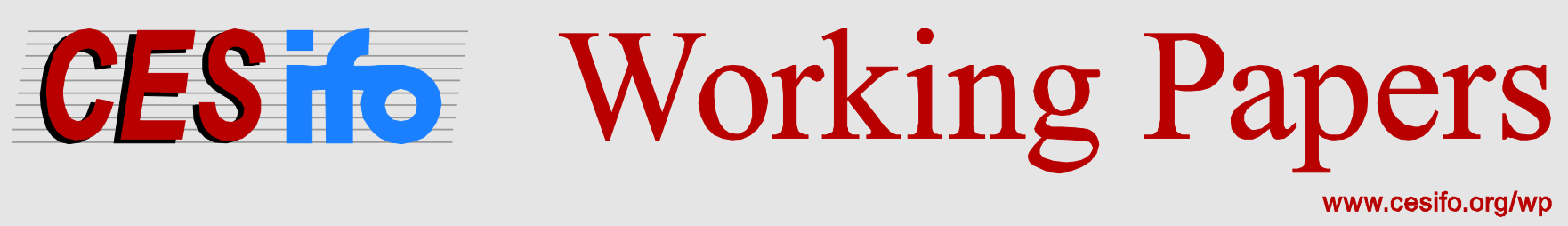

\title{
When Ignorance is Bliss \\ Information Asymmetries Enhance Prosocial Behavior in Dictator Games
}

\author{
Evguenia Winschel \\ Philipp Zahn
}

\section{CESIFO WORKING PAPER NO. 4750 \\ CATEGORY 13: BEHAVIOURAL ECONOMICS \\ APRIL 2014}

Presented at CESifo Conference on Social Economics, March 2014

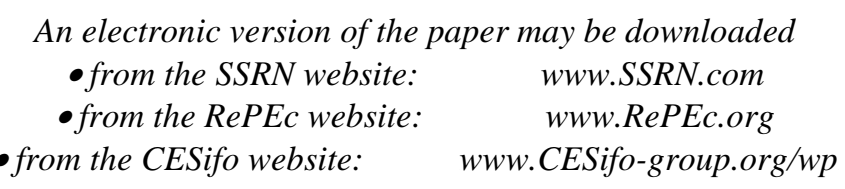




\title{
When Ignorance is Bliss Information Asymmetries Enhance Prosocial Behavior in Dictator Games
}

\begin{abstract}
In most laboratory experiments concerning prosocial behavior subjects are fully informed how their decision influences the payoff of other players. Outside the laboratory, however, individuals typically have to decide without such detailed knowledge. To assess the effect of information asymmetries on prosocial behavior, we conduct a laboratory experiment with a simple non-strategic interaction. A dictator has only limited knowledge about the benefits his prosocial action generates for a recipient. We observe subjects with heterogenous social preferences. While under symmetric information only individuals with the same type of preferences transfer, under asymmetric information different types transfer at the same time. As a consequence and the main finding of our experiment, uninformed dictators behave more prosocially than informed dictators.
\end{abstract}

JEL-Code: D820, C910.

Keywords: asymmetric information, prosocial behavior, efficiency concern, inequality aversion, dictator game.

Evguenia Winschel

University of Mannheim

Department of Economics

L7 3-5

Germany - 68131 Mannheim

eugeniaw@rumms.uni-mannheim.de
Philipp Zahn

University of Mannheim

Department of Economics

L7 3-5

Germany - 68131 Mannheim

philipp.zahn@econ.uni-mannheim.de

March 2014

We thank Dirk Engelmann, Hans Peter Grüner, seminar participants at the University of Mannheim, and the CESifo conference on social economics for helpful comments and suggestions. We gratefully acknowledge financial support from the Deutsche Forschungsgemeinschaft (DFG) through SFB 884 "Political Economy of Reforms". 


\section{Introduction}

In experiments such as the Ultimatum Game, the Trust Game, or the Dictator Game subjects regularly deviate from a selfish maximization of payoffs and behave prosocially (Camerer, 2003). The laboratory experiments providing evidence for social preferences are conducted in an environment where agents have full information about the costs and benefits for everyone. However, outside the lab, in many situations where people behave prosocially, individuals are better informed about how their decisions affect their own payoff than how they affect others.

Let us consider charity. While a donor has a clear idea of his own costs, he often is not certain about the actual consequences of his decision to donate. For instance, when donating to aid organizations in developing countries, donors may be concerned whether the money is spent on the most effective projects and not just wasted. Or they may be concerned that money designated to help people who need the money the most ends up in other pockets.

Consider another example: redistribution through the tax system. There is experimental evidence that prosocial concerns are important when individuals collectively decide about taxes and redistribution (e.g., Tyran and Sausgruber, 2006; Sauermann and Kaiser, 2010; Höchtl et al., 2012). While subjects face strategic uncertainty in these experiments, they are perfectly informed about the payoff consequences for others. In the field, individuals have fewer information at hand when making a decision. They will be well informed how they themselves are affected, but they do not necessarily know the exact consequences for others, let alone the overall effect on the income distribution.

In this paper, we investigate the prosocial behavior of a dictator who is only imperfectly informed about the consequences of his decisions on others. We conduct a laboratory experiment with the following design. Two subjects, $A$ and $B$, are matched; both subjects have an initial endowment; $A$ makes a binary decision whether or not to 
make a monetary transfer to $B$. The transfer causes known costs for $A$ and benefits for $B$, with the benefits being larger than the costs. As treatment we vary the information $A$ has about the benefit level. While $A$ is informed about the exact level of the benefit in the control setting, he does not know the exact level of it in the treatment.

Our main finding is that, on average, subjects $A$ behave more prosocially when they do not know the benefit level compared to the situation when they know the benefit level. More subjects transfer under asymmetric information than under symmetric information.

We provide a simple explanation for this finding based on social preference theories. Under symmetric information a substantial share of individuals (40\%) behaves prosocially and they are heterogeneous in their preferences. Subjects $A$, whose choices are consistent with inequality aversion (Fehr and Schmidt, 1999), transfer only up to a certain benefit level, so that the payoffs of players $B$ do not exceed that of players $A$. In contrast, subjects $A$, whose choices are consistent with an efficiency concern or maximin preferences (Charness and Rabin, 2002), transfer only starting from a certain level of benefit, when the degree of efficiency is sufficiently high. Hence, in our setting they rarely transfer simultaneously under symmetric information. Under asymmetric information, however, both types transfer at the same time even though they face a risk what benefit level realizes in the end.

Our results give a novel perspective on the social preference literature. In contrast to populations of selfish individuals where the effect of asymmetric information is well understood, in a population with prosocial individuals the effect is not straightforward. With our experiment we provide evidence that results can realize which are counterintuitive at first glance but in fact can be explained by existing theories. When different types of prosocial preferences are present in a population, then, depending on the frequency of types and the intensities of their prosocial concern, we can obtain significantly more 
prosocial decisions under asymmetric information than under symmetric information.

To the best of our knowledge we provide the first experimental design in which an information asymmetry regarding the degree of efficiency is introduced in a basic nonstrategic setting. In contrast to existing experiments, in our work only the information available to the dictator varies, while $B$ is fully informed. $A^{\prime} s$ decision neither makes his own payoff nor $B^{\prime} s$ payoff more risky.

The paper is organized as follows. In the next section, we discuss the related literature. In Section 3, we present the experimental design followed by a discussion of behavioral hypotheses in Section 4. We present in the main results in Section 5. In Section 6 we provide robustness checks for our results and conclude in Section 7.

\section{Related Literature}

The experimental evidence regarding prosocial behavior in simple two-persons experiments such as the Trust Game, the Ultimatum Game, and the Dictator Game is extensive. The central and robust findings demonstrate that subjects regularly deviate from purely selfish behavior though to varying degrees (e.g., Camerer, 2003).

A few papers (e.g., Mitzkewitz and Nagel, 1993; Rapoport and Sundali, 1996; Huck, 1999; Güth et al., 1996) introduce asymmetric information regarding the amount of money to be distributed in simple two-persons dictator games. In contrast to our experiment, however, the asymmetric information is on the recipient side. Only in Klempt and Pull (2009), the information asymmetry is on the side of the proposer. In this paper an uninformed proposer runs a risk that the demand of a too high share to himself leads to a his own transfer equal to zero when the actual amount of money to be distributed is small.

The first treatment in Dana and Weber (2007) presents an experiment similar in design to our paper with regard to the information asymmetry. In their setting, a dictator has 
to make a choice between two allocations where he initially only observes his own payoff but does not observe the recipient's payoff. Dictators can choose to be informed about the recipient's payoff before they make a decision while the recipient is neither aware of the dictator's choice to find out the information nor of his transfer decision. Dana and Weber (2007) find that a significant share of dictators prefer to remain uninformed and more often decide to behave selfishly compared to the benchmark where dictators are informed about the recipient's payoff right from the beginning. Hence, Dana and Weber (2007) provide evidence that subjects just want to appear as prosocial instead of "truly" being altruistic. ${ }^{1}$

In our experiment a recipient is perfectly informed about the level of his benefit in the case of prosocial decision and about dictators' behavior. The dictator, in contrast, does not know the benefit level and he has no possibility to find it out. Moreover, in Dana and Weber (2007) the choices that imply the more equal and the efficient distribution are the same. In our case, while the choice is always efficiency increasing, its distributional consequences vary over different values of $b$.

A recent strand of literature (Brock et al., 2013; Brennan et al., 2008; Güth et al., 2008; Bradler, 2009) investigates how risk regarding other subjects' payoffs affects prosocial behavior. Brock et al. (2013) design an experiment where the dictator can choose to give up some of his payoff in oder to increase payoff chances of the recipient. The goal of their experiment is to evaluate whether ex-ante or ex-post fairness concerns are relevant for dicators' decisions under risk. ${ }^{2}$ They find that decisions are not only driven by ex-post concerns (as in the model of Fehr and Schmidt (1999)) but also by ex-ante concerns. In the experiment of Brennan et al. (2008), a dictator has to make choices among lotteries

\footnotetext{
${ }^{1}$ There are several other papers that investigate whether subjects are more selfish when the actions of dictators are not fully observable (e.g., Andreoni and Bernheim (2009) and the "multiple dictator" treatment as well as the "plausible deniability" treatment in Dana and Weber (2007)). They find a significantly less generous behavior of dictators relative to the standard game thus also supporting the view that subjects are not truly prosocial but want to appear as such.

${ }^{2}$ On social preferences and ex-ante as well as ex-post fairness concerns see the axiomatic treatment of Fudenberg and Levine (2012).
} 
over his and recipients' payoffs. Hereby, attitudes towards private and collective risks can be evaluated. Each dictator is required to evaluate four different allocations. Each allocation assigns a payoff to the dictator and to the recipient either in a probabilistic or in a deterministic way. ${ }^{3}$ The experiment shows that dictators' behavior is significantly different when they face risks regarding their own payoff compared to a situation with no risk for them personally. Yet, the authors do not find evidence that the risk, recipients are exposed to, affects dictators' decisions. ${ }^{4}$

In our setting, under asymmetric information the dictator has to make a decision when he does not know the already determined payoff for the recipient while in Brock et al. (2013); Brennan et al. (2008); Güth et al. (2008) dictators affect the payoff risks/chances of others. In Brock et al. (2013) dictators' choices are between giving up some of their payoff in order to increase payoff chances of recipients. In Brennan et al. (2008); Güth et al. (2008) two different kinds of risk concerns regarding the others' payoff are intertwined. First, as those papers posit, it may be that dictators put themselves in the shoes of others and do not want to expose recipients to risk. Secondly, however, if subjects exhibit social preferences based on outcomes, then they face a risk themselves. When choosing a lottery, they face an uncertain outcome regarding the others' payoff directly affecting their own utility. In the above designs, both effects are mixed up and not distinguishable. Moreover, a dictator is exposed to direct risks that affect his own payoff as well, which can influence his attitude towards the risk of the recipient. In our approach the exposure of the recipient to a possible risk and the influence of the direct risk on the dictator are absent which allows us to separate out the effect we are interested in: an uncertain outcome regarding the others' payoff.

\footnotetext{
${ }^{3}$ Güth et al. (2008) conducted a similar experiment where they added another dimension: time preferences.

${ }^{4}$ Rohde and Rohde (2011) similarly find only weak evidence that the risk, recipients' are exposed to, influences dictators. Results by Bradler (2009) indicate that subjects are willing to risk parts of their own payoff when they can thereby increase the payoff of the recipient from zero or from a very small amount.
} 


\begin{tabular}{l|l|l}
\hline \hline $\begin{array}{l}\text { Baseline } \\
\text { Sessions }\end{array}$ & $\begin{array}{l}\text { Robustness } \\
\text { Sessions }\end{array}$ & Treatments \\
\hline $\begin{array}{l}\text { Part 1 } \\
\text { Part 2 }\end{array}$ & Part 4 & $\begin{array}{l}b \text { is not known to } A \\
b \text { is not known to } A . A \text { re- } \\
\text { ceives a reward if he trans- } \\
\text { fers. }\end{array}$ \\
Part 3 & Part 3 & $\begin{array}{l}b \text { is known to } A . A \text { receives } \\
\text { a reward if he transfers. } \\
b \text { is known to } A .\end{array}$ \\
Part 4 & Part 1 \\
\hline \hline
\end{tabular}

Table 1: Overview over the Sequence of Treatments in the 4 Parts of the Experiment.

\section{Experimental Design}

We implement the following experimental design. There are two agents, $A$ and $B$. $A$ has an endowment, $e_{A}$, of 100 points (100 points are equivalent to 10 EUR), $B$ has an endowment, $e_{B}$, of 50 points. Only $A$ makes a (binary) decision. He can decide whether he wants to transfer 20 points. If $A$ transfers, $B$ receives a benefit $b$, with $b \in\{25,30,40,50,60,70\}$. We choose such initial endowments that a transfer always results in an efficiency gain and a decrease in inequality for low values of $b(b \leq 30)$. For values of $b>30$ inequality increases in $b$. Hence, depending on the exact value of $b$ a decision to transfer can be motivated by a concern for efficiency or by a concern for equality.

The experiment consists of 4 parts. Table 1 provides an overview over the parameters that change in each part. ${ }^{5}$

\subsection{Treatments}

The main treatment variable in our experiment is whether $A$ knows the exact benefit $b$ when he makes a decision or whether his knowledge about $b$ is limited to the distribution from which $b$ is drawn.

\footnotetext{
${ }^{5}$ See Section 6 for a discussion of the robustness sessions.
} 
In part 1, participants $A$ have to make a decision under asymmetric information with respect to $b$. The exact value of $b$ is determined in the following way. Participants are presented an urn from which a value for $b$ is drawn before subjects make a decision. The urn contains the following balls each representing one value of $b: 25,30,40,50,60,70$. Agent $A$ is not informed about the ball which is drawn while it is disclosed to agent $B$. Moreover, it is commonly known that $B$ observes the exact benefit. Subjects make only one decision whether to transfer or not.

In part 4 , participants $A$ make decisions under symmetric information. That is, each $A$ knows the exact value of $b$. We use the strategy method to elicit a complete response by subject $A$ for each value of $b(25,30,40,50,60,70)$. This is crucial because it allows us to describe the values of $b$ for which subjects are willing to transfer under symmetric information and whether their behavior is consistent with their decision under asymmetric information. Subjects have to make one decision (transfer yes/no) for each level of $b$. After they had made their decisions, one ball from the urn was drawn and determined which decision was payoff-relevant for part 4.

Part 2 (3) is identical to part 1 (4), but as an additional treatment we introduce a reward for $A$ if he transfers 20 points. There exists substantial experimental evidence that incentives can "crowd out" prosocial behavior (e.g., Gneezy and Rustichini, 2000; Frey and Oberholzer-Gee, 1997). ${ }^{6}$ We want to test whether the incentive has the same effect under symmetric and asymmetric information. Under asymmetric information the incentive could interact with the uncertainty. Subjects could "perceive" the reward level as being related to the unknown benefit level and interpret the reward as a signal (Bolle and Otto, 2010). In part 2, the reward $r$ could take on two values, $r_{L}=5$ and $r_{H}=10$. The subjects only know that $r \in\{5,10\}$ and that the exact value of $r$ was determined after $b$ had been drawn, but they do not know how the reward was chosen. In fact,

\footnotetext{
${ }^{6}$ See Bowles and Polanía-Reyes (2012); Gneezy et al. (2011) for surveys of the literature.
} 
the reward was determined by a lottery after $b$ had been drawn. ${ }^{7}$ After the reward is determined, all subjects are informed about the exact value of $r$. In part 3, the reward was fixed with $r=5$. Before making a decision, subjects always observe the exact value of $r$.

At the end of the experiment, one of the four parts was randomly drawn. This part determined the final payoff of participants.

In our experiment subjects participate in different treatment conditions sequentially. It is therefore possible that decisions in part $2-4$ are influenced by previous rounds. To control for this possibility, we ran robustness sessions where we change the order of treatments (see Table 1).

As, qualitatively, results are very similar in the baseline and the robustness sessions, we pool the sample and use it for our main analysis. To avoid confusion, in the main analysis, we refer to "part 1" comprising all observations under asymmetric information without reward from baseline and robustness sessions (and analogously for part 2, 3, and 4). In Section 6.2 we investigate the two samples separately.

\subsection{Procedural Details}

Subjects were randomly assigned to either role A or role B at the beginning of the experiment. ${ }^{8}$ They kept this role over the course of the experiment. Subjects knew that the experiment comprised four parts, but they did not know the content of each part in advance. Subjects received separate instructions at the beginning of each part.

We ran five baseline sessions with 90 subjects and three more robustness sessions with 60 subjects. The experiments were conducted at the experimental laboratory at the University of Mannheim in March - May 2012 (baseline sessions) and in November

\footnotetext{
${ }^{7}$ The probability is $1 / 10$ for the high reward and $9 / 10$ for the low reward. In all sessions $r=5$ was drawn

${ }^{8}$ Subjects $B$ had no decision to make in the experiment, but we elicited their beliefs about what they thought subjects $A$ would do.
} 
2012 (robustness sessions). The experiment was computerized using z-tree (Fischbacher, 2007). Subjects were students from different fields at the University of Mannheim. They were recruited using the online system ORSEE (Greiner, 2004). Each session took between 35 and 40 minutes and comprised 16-20 subjects. The average earnings were 7.80 EUR.

\section{Behavioral Predictions}

Our main question is how the introduction of asymmetric information influences aggregate and individual behavior. Do subjects transfer more often or less often under asymmetric information?

We begin with a discussion how subjects $A$ behave under symmetric information (part 4). We do not expect that behavior will follow only one type of preferences as heterogeneous types have been found in other experiments (see, for instance, Kamas and Preston, 2012; Engelmann and Strobel, 2007). We focus on three possible motives for prosocial behavior that are prominent in the literature: efficiency concern, maximin preferences (Charness and Rabin, 2002), and inequality aversion (Fehr and Schmidt, 1999). ${ }^{9}$

When subjects have a concern for efficiency, they will trade-off their costs with the benefits and the consequent efficiency gain. Hence, the more an individual $i$ cares for efficiency the lower the minimal value of $b$ for which $i$ would transfer. Thus, subjects with an efficiency concern should exhibit the following transfer pattern. Either they do not transfer at all or they transfer for a particular value of $b^{*}$ and all values $b>b^{*}$.

The transfer pattern of subjects with maximin preferences is similar to the transfer pattern of efficiency concern. Either they do not transfer at all, or they transfer for a particular value of $b^{*}$ and all values $b>b^{*}$. In contrast to efficiency concern, there are

\footnotetext{
${ }^{9}$ Cf. Appendix B for a detailed analysis of the utility functions.
} 
only two thresholds: either $b^{*}=30$ or $b^{*}=25$.

The specification of Fehr and Schmidt (1999) can lead to behavior consistent with transfers for low values of $b$ but no transfers once the benefit level is above 50 .

What behavior can we expect for different types of social preferences under asymmetric information? Under asymmetric information $A$ does not know the value of $b$. Given the lottery which determines the value of $b$, the expected value is roughly 45 . The utility functions we consider are not linear (apart from efficiency concern), but given our parameters they imply that under asymmetric information subjects behave as under symmetric information when the benefit is equal to its expected value. Subjects transfer if and only if they transfer under known $b=45$.

However, under asymmetric information subjects face a risk. If they transfer, a value of $b$ can realize for which they would not transfer if they knew it for certain. Alternatively, they can behave selfishly and do not transfer. Then, they risk that they choose not to transfer for a value of $b$ under which they would transfer if they had the information available. As it is the case with decisions where solely their own payoff is at risk, subjects in our design may be affected by the risk regarding the other's payoff and deviate from the CR/FS predictions. ${ }^{10}$ In this case, we will observe a more selfish behavior at the individual level when they are negatively affected by risk.

So far, we assumed that the subjects' behavior follows the standard approach: maximization of utility functions with the additional ingredient of social preferences. There is, however, an alternative approach based on cognitive dissonance theory (Konow, 2000) which has been used to explain behavior in the dictator game and which could become relevant in particular under asymmetric information. According to this theory, subjects want to achieve a high payoff for themselves and to behave fair at the same time. They experience dissonance when decisions have to be made where these two objectives are

\footnotetext{
${ }^{10}$ Note that neither Fehr and Schmidt (1999) nor Charness and Rabin (2002) discuss the possibility of risk regarding the others' payoffs and it is not obvious how to implement it within their framework.
} 
in conflict. Moreover, "[t]he agent is motivated to reduce dissonance and may, generally speaking, do so by altering behavior, e.g., when the dictator takes less, and/or by changing beliefs, e.g., when the dictator believes it is fair to take more than the fair amount." (Konow, 2000, p. 1076). Under symmetric information subjects are exposed to dissonance of being nice and keeping the money for themselves. Under asymmetric information the dissonance may be partly resolved by the uncertainty about $b$. Subjects have some "moral wiggle room" (Dana and Weber (2007)) to justify selfish behavior, because values of $b$ may realize under which the subjects feel less compelled to transfer. Hence, they may reduce transfers compared to the symmetric information situation and behave less prosocially than the CR/FS predictions.

\section{Results}

Do subjects behave differently under symmetric and asymmetric information? The first bar in Figure 1 depicts the fraction of individuals transferring in part 1 under asymmetric information. Comparing it to the behavior under symmetric information (part 4, represented by bars 2 to 7 ), especially to the intermediate benefit levels, subjects are more likely to transfer money. Under symmetric information for benefit levels from $b=25$ to $b=70$ only $20,17,15,21,23$ and $28 \%$ of all subjects are willing to transfer money compared to $31 \%$ under asymmetric information.

Table 2 depicts results of an OLS regression with the individual transfer decision as dependent variable. As independent variables we include the benefit levels under symmetric information, the omitted category is the decision under asymmetric information. The regression confirms what the graph already pointed to. Fewer prosocial decisions are made under symmetric information compared to the case of asymmetric information. The differences for benefit levels below 60 are statistically significant. ${ }^{11}$

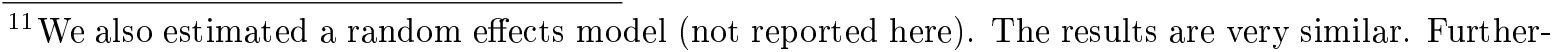


Figure 1: Percentage of Transfers - Asymmetric vs Symmetric Information

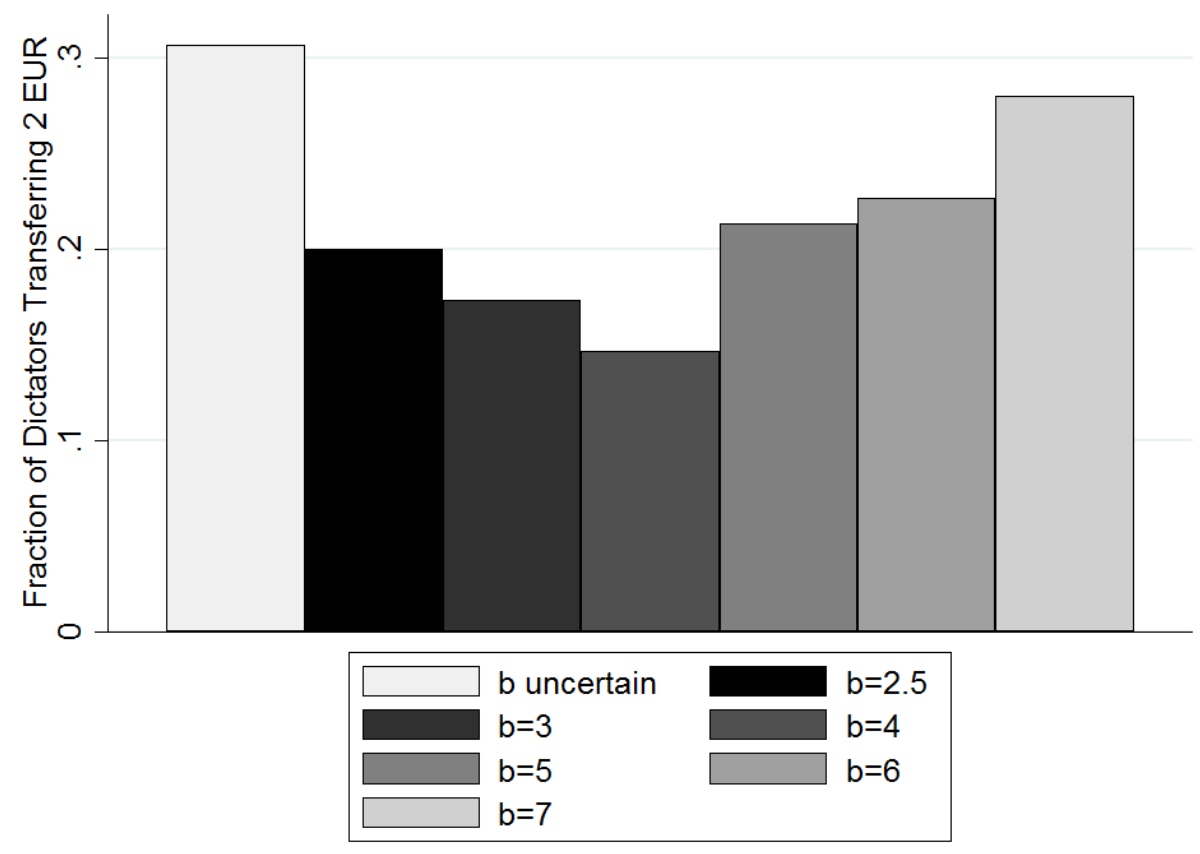

Notes: The figure depicts the share of subjects $A$ who transfer. The first bar refers to transfers under asymmetric information without reward. Bars 2-7 depict transfers for each level of benefit under symmetric information without reward. $N=75$. 
Table 2: Dictators' Transfer Decision

\begin{tabular}{|c|c|}
\hline & (1) \\
\hline Transfer when benefit $=25(=1)$ & $\begin{array}{c}-0.107^{* *} \\
(0.0525)\end{array}$ \\
\hline Transfer when benefit $=30(=1)$ & $\begin{array}{c}-0.133^{* * *} \\
(0.0480)\end{array}$ \\
\hline Transfer when benefit $=40(=1)$ & $\begin{array}{c}-0.160 * * * \\
(0.0469)\end{array}$ \\
\hline Transfer when benefit $=50(=1)$ & $\begin{array}{c}-0.0933^{*} \\
(0.0474)\end{array}$ \\
\hline Transfer when benefit $=60(=1)$ & $\begin{array}{l}-0.0800 \\
(0.0496)\end{array}$ \\
\hline Transfer when benefit $=70(=1)$ & $\begin{array}{c}-0.0267 \\
(0.0539)\end{array}$ \\
\hline Constant & $\begin{array}{c}0.307^{* * *} \\
(0.0539)\end{array}$ \\
\hline$N$ & 525 \\
\hline
\end{tabular}

Notes: Standard errors are in parentheses. Table reports results from an OLS regression. Dependent variable is the individual transfer decision. Explanatory variables are the benefit levels under symmetric information. The omitted category is the asymmetric information case. Standard errors are clustered at the subject level.

Level of significance: ${ }^{*} \mathrm{p}<0.10,{ }^{* *} \mathrm{p}<0.05,{ }^{* * *} \mathrm{p}<0.01$ 
From Figure 1 and Table 2 it is clear, that, on average, subjects are more willing to transfer when they do not know the exact value of $b$. In the following, we discuss why we observe this difference. It is a combination of several effects. First, we observe heterogeneous transfer patterns as predicted by different social preference theories. We can assign each dictator to one of four patterns. ${ }^{12}$ Selfish subjects who do not transfer for any benefit level (60\% of all subjects), subjects who transfer for all values of $b$ and whose behavior is thereby in accordance with a concern for efficiency as well as maximin preferences $(7 \%)$. Moreover, we observe subjects whose behavior is in line with an efficiency concern but not with maximin preferences (20\%) and subjects whose behavior is in line with inequality aversion $(13 \%) .{ }^{13}$

It is important to note that when $b$ is known, different subjects transfer for different values of $b$. For low values of $b$, subjects whose behavior is consistent with inequality aversion transfer. They do not transfer, though, when the benefit reaches a certain threshold. In contrast, subjects whose behavior is in line with an efficiency concern transfer starting from a certain threshold. In Figure 2 we show that the share of individuals with inequality aversion or efficiency concern changes with the value of $b .{ }^{14}$

The second element that leads to higher transfers under asymmetric information is as follows. As implied by the social utility functions most individual transfers are not negatively affected by risk. According to these functions all subjects who transfer under $b=40$ and $b=50$ should transfer under asymmetric information as well. We observe eight such subjects (this number does not include $7 \%$ of subjects who always transfer, regardless of $b$ ) and all of them transfer under asymmetric information. Hence, every subject who should behave prosocially according to social preferences chooses to do

more, we did a Wilcoxon signed-rank test. For benefit levels 30 and 40 the null-hypothesis can be rejected at the $1 \%$ level, for $b=25$ and $b=50$ at the $5 \%$ level, and for $b=60$ at the $10 \%$ level.

${ }^{12}$ The assignment is based on behavior in part 4 .

${ }^{13}$ We have 150 pairs and thereby 75 dictators. 40 are selfish, 15 behave according to efficiency concern, 5 to either efficiency concern or maximin preferences, and 10 according to inequality aversion.

${ }^{14} \mathrm{By}$ definition the patterns for other groups are degenerate. Either subjects transfer for all values of $b$ or for none. 
Figure 2: Transfer Patterns for Different Values of $b$

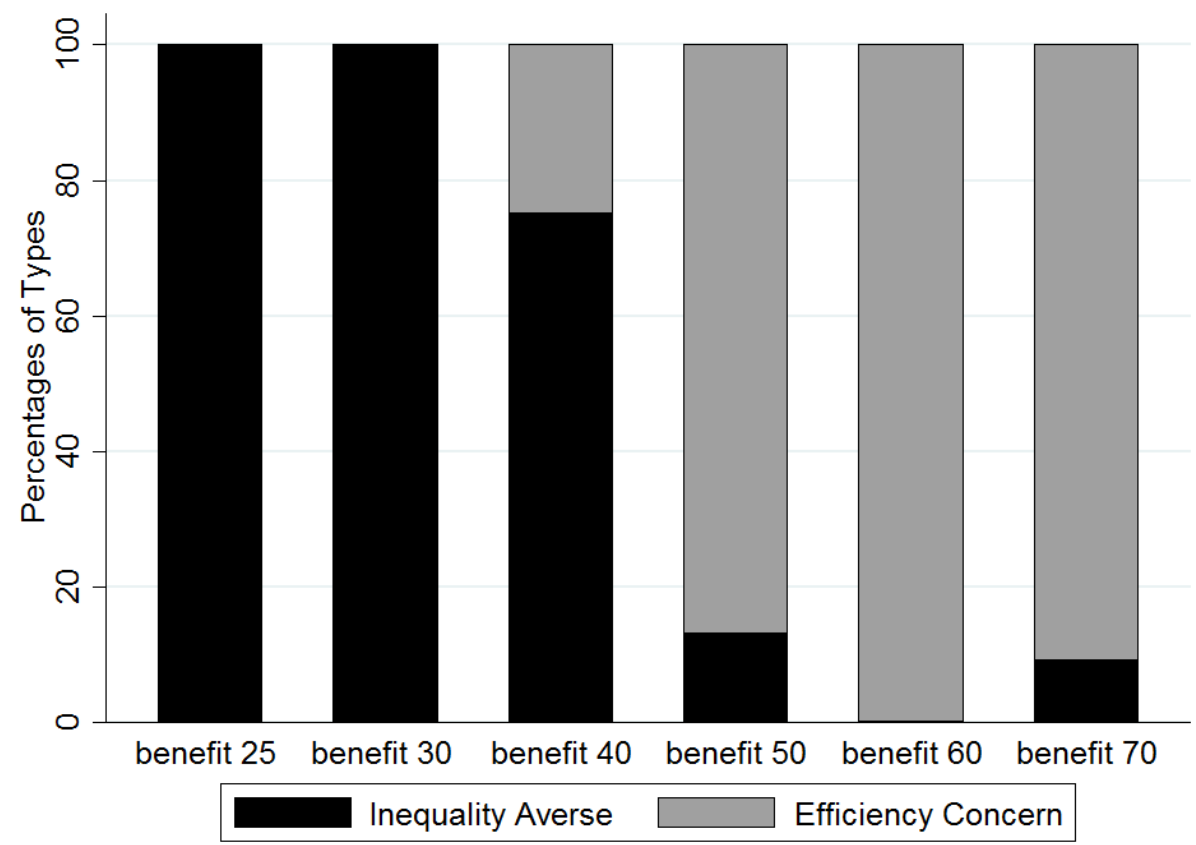

Notes: The sample is restricted to those subjects whose behavior follows the prediction by either efficiency concern or inequality aversion. The exact level of $b$ is known. One subject only transferred at $b$ smaller than 40 but also for the value of $b=70$ in part 4. We assigned this subject to pattern "inequality aversion". 
so. Moreover, we observe eleven subjects who transfer either under $b=40$ or under $b=50$ under symmetric information. For these subjects both decisions, transfer and no transfer, would be in line with social preferences under asymmetric information. In fact, seven out of these eleven transfer. Lastly, we find 16 subjects who are not egoists but transfer neither for $b=40$ nor for $b=50$, so they should not transfer under an expected value $b=45$. Eight of them transfer nevertheless. So, if at all, we find some evidence for increased prosocial behavior under asymmetric information and there is no evidence for a negative effect of asymmetric information.

Combining that, first, subjects are not negatively affected by asymmetric information and, second, that the parameters of our experiment are such that two different types of subjects separate for known transfers under symmetric information but both transfer when the information is asymmetric, can explain the higher transfers under asymmetric information. $^{15}$

As a consequence, earnings for subjects $B$ are substantially higher when $A$ decide under asymmetric information. Each value of $b$ is equally likely and the unconditional decision to transfer $(0.31)$ is the same for all values of $b$. Under symmetric information, each value of $b$ is also equally likely as before. Yet, as subjects make a transfer decision for each value of $b$, the conditional probability may vary over $b$ and is smaller than the probability under asymmetric information. Hence, players $B$ have a higher chance to obtain a transfer: $31 \%$ under asymmetric information versus $21 \%$ under symmetric information. ${ }^{16}$ And their expected transfer is $40 \%$ higher: 10 points under symmetric information versus 14 points under asymmetric information. ${ }^{17}$

\footnotetext{
${ }^{15}$ Given that we observe higher transfers under asymmetric information, it is also clear that the type of information asymmetry we introduce is not sufficient to make subjects behave more selfish due to more "moral wiggle room" as, for instance, in Dana and Weber (2007).

${ }^{16}$ Probability to obtain a transfer is equal to $\frac{1}{6}(20+17+15+21+23+28) \%=21 \%<31 \%$

${ }^{17} E[b]=\frac{1}{6}(0.2 \cdot 25+0.17 \cdot 30+0.15 \cdot 40+0.21 \cdot 50+0.23 \cdot 60+0.28 \cdot 70)=10<0.31 \cdot 45=13.95$
} 


\section{Robustness Check}

In this section we briefly discuss the effect of the reward and check for order effects in the sequence of the four parts. All results can be found in the Appendix C.

\subsection{Reward}

The introduction of a reward in parts 2 and 3 has a positive effect. More subjects choose to transfer money in part 2 compared to part 1 (cf. Appendix C.1, Figure 3). Mirroring the positive effect, when the reward is withdrawn, we observe a negative effect. The willingness to transfer decreases. For each value of $b$ we observe fewer transfers in part 4 than in part 3. The results of an OLS regression (Table 5 in Appendix C.1) confirm that the reward has a positive effect and that it is statistically significant.

We observe no "crowding out effect", neither due to a framing effect nor due to signaling. Moreover, treatments 2 and 3 serve as robustness check for the main treatments 1 and 4 . When we compare transfers under symmetric and asymmetric information, we observe the same behavior pattern as while comparing 1 and 4 .

\subsection{Sequence of Parts}

As in our experiment subjects participate in different treatments in a sequence, it may be possible that subjects' behavior is influenced by the order of treatments. To check the robustness of our results, we ran three sessions with 60 participants where we changed the order of the parts. Most importantly, we let subjects decide first under symmetric information. Hence, we can compare this decision to the baseline sessions where subjects decided under asymmetric information in part 1 . In the main analysis we pooled this data with the baseline sessions. In the following, we compare the two samples.

A direct comparison between transfer levels reveals that under asymmetric information in the first treatment subjects transfer more than for each level of benefit $b$ under 
symmetric information (cf. Appendix C.2, Figure 4). ${ }^{18}$

When we compare the baseline sessions with the robustness sessions, we find no statistically significant differences. Yet, small differences exist. In the robustness sessions subjects transfer less in all treatments and the effect of asymmetric information is not so strong (cf. Figure 5 and Figure 6 in Appendix C.2). The reasons are that, first, we observe a smaller percentage of subjects with prosocial preferences. Secondly, we observe a different composition of types. There are relatively more subjects with inequality aversion and fewer with efficiency concern. As a result, we have relatively less subjects who transfer under $b=40$ or/and under $b=50$. Hence, it is not surprising that the average willingness to transfer under asymmetric information is not so strong in the robustness sessions. This result also serves as a nice illustration of the complex interaction between heterogeneity of types and asymmetric information. Regarding individual behavior, the reaction to asymmetric information is very similar in the baseline sessions and the robustness sessions.

\section{Conclusion}

In most laboratory experiments concerning prosocial behavior subjects have plenty of information available how their actions influence other subjects' payoffs. In this paper, we investigate what results when individuals are only imperfectly informed. We compare transfers when a dictator has perfect information about the benefit he generates for the recipient with a situation where he only knows the distribution of benefits that may realize. The recipient, however, is fully informed about the benefit he receives.

We find that (i) in this setting $40 \%$ of subjects behave prosocially and transfer, (ii) $20 \%$ of subjects make choices that are consistent with a concern for efficiency, $13 \%$ make

\footnotetext{
${ }^{18}$ For $b=30, b=50$, and $b=60$ the difference is statistically significant (Fisher's exact test, $p<0.10$ ) and for $b=40$ as well (Fisher's exact test, $p<0.05$ ).
} 
choices which are consistent with inequality aversion, and $7 \%$ transfer independently of the value of $b$, whose choices are therefore in line with an efficiency concern or maximin preferences, and (iii) under asymmetric information transfers do not decline. Even though subjects face the risk of transferring at a benefit $b$ which they would not choose if they knew $b$ for sure, the level of transfers is stable and in fact even higher than the highest transfer level under symmetric information.

Our results suggest that individual behavior is not negatively affected by asymmetric information. In the aggregate, subjects, whose behavior is either in line with inequality aversion or with an efficiency concern, both tend to transfer under asymmetric information. Consequently, more subjects transfer under asymmetric information than for any $b$ under symmetric information. Our results therefore do not provide evidence that subjects exploit the uncertain benefit level in order to justify selfish behavior and in order to resolve a cognitive dissonance.

The general lesson our results point to is the complex embedding of information asymmetries in interactions when social preferences are not homogenous. In our setting, asymmetric information leads to convergent choices and thereby increased prosocial behavior for subjects with different types of social preferences. However, one can also think of situations where this will not happen, for instance with individuals who exhibit different thresholds than the ones observed in our experiment, with allocations that have a larger range of possible benefits, or with different lotteries. Then, under asymmetric information overall support may not be larger than for each value of $b$.

There are several avenues for further research. To begin with, it would be interesting to explore further whether in alternative settings asymmetric information can produce opposite results where prosocial behavior decreases under information asymmetries. Furthermore, it would be of interest to consider strategic interactions where not only one dictator makes a decision but the recipient or a whole group jointly has to make 
a decision. There is experimental evidence that social preferences influence individual decisions when subjects have to decide collectively for or against policy proposals, in particular in the domain of tax policies and redistribution (e.g., Tyran and Sausgruber, 2006; Sauermann and Kaiser, 2010; Höchtl et al., 2012). In the light of our results, it would be interesting to extend our framework to a setting where a group makes a decision by voting instead of one dictator deciding alone. Often, policy proposals are plagued with information asymmetries - individuals will be better informed about how a reform affects themselves than how it affects others - and we could explore how information asymmetries affect prosocial behavior in this situation.

\section{References}

Andreoni, James and B. Douglas Bernheim, "Social Image and the 50-50 Norm: A Theoretical and Experimental Analysis of Audience Effects," Econometrica, 2009, $77(5), 1607-1636$.

Bolle, Friedel and Philipp E. Otto, "A Price Is a Signal: On Intrinsic Motivation, Crowding-Out, and Crowding-In," Kyklos, 2010, 63 (1), 9-22.

Bowles, Samuel and Sandra Polanía-Reyes, "Economic Incentives and Social Preferences: Substitutes or Complements?," Journal of Economic Literature, June 2012, $50(2), 368-425$.

Bradler, Christiane, "Social Preferences under Risk - An Experimental Analysis," Working Paper 09, ZEW Discussion Papers 2009.

Brennan, Geoffrey, Luis G. González, Werner Güth, and M. Vittoria Levati, "Attitudes Toward Private and Collective Risk in Individual and Strategic Choice 
Situations," Journal of Economic Behavior $\&$ Organization, July 2008, 67 (1), 253262.

Brock, J. Michelle, Andreas Lange, and Erkut Y. Ozbay, "Dictating the Risk: Experimental Evidence on Giving in Risky Environments," American Economic Review, 2013, 103 (1), 415-37.

Camerer, Colin F., Behavioral Game Theory: Experiments in Strategic Interaction., Roundtable Series in Behavioral Economics., 2003.

Charness, Gary and Matthew Rabin, "Understanding Social Preferences with Simple Tests," Quarterly Journal of Economics, 2002, 117 (3), 817-869.

Dana, Jason and Roberto A Weber, "Exploiting Moral Wiggle Room: Experiments Demonstrating an Illusory Preference," Economic Theory, 2007, pp. 67-80.

Engelmann, Dirk and Martin Strobel, "Preferences over Income Distributions: Experimental Evidence," Public Finance Review, 2007, 35 (2), 285-310.

Fehr, Ernst and Klaus M Schmidt, "A Theory Of Fairness, Competition, and Cooperation," Quarterly Journal of Economics, 1999, 114 (3), 817-868.

Fischbacher, Urs, "z-Tree: Zurich Toolbox for Ready-Made Economic Experiments," Experimental Economics, February 2007, 10 (2), 171-178.

Frey, Bruno S. and Felix Oberholzer-Gee, "The Cost of Price Incentives: An Empirical Analysis of Motivation Crowding-Out," American Economic Review, 1997, $87(4), 746-755$.

Fudenberg, Drew and David K. Levine, "Fairness, risk preferences and independence: Impossibility theorems," Journal of Economic Behavior \& Organization, 2012, $81(2), 606-612$. 
Gneezy, Uri and Aldo Rustichini, "A Fine Is a Price," J. Legal Stud., 2000, 29 (1), $1-17$.

_ , Stephan Meier, and Pedro Rey-Biel, "When and Why Incentives (Don't) Work to Modify Behavior," Journal of Economic Perspectives, 2011, 25 (4).

Greiner, Ben, "The Online Recruitment System ORSEE 2 . 0 - A Guide for the Organization of Experiments in Economics," Working Paper 10, Working Paper Series in Economics, University of Cologne, Department of Economics 2004.

Güth, Werner, M. Vittoria Levati, and Matteo Ploner, "On the Social Dimension of Time and Risk Preferences: an Experimental Study," Economic Inquiry, April 2008, $46(2), 261-272$.

_ , Steffen Huck, and Peter Ockenfels, "Two-Level Ultimatum Bargaining with Incomplete Information: An Experimental Study," Economic Journal, 1996, 106 (436), $593-604$.

Höchtl, Wolfgang, Rupert Sausgruber, and Jean-Robert Tyran, "Inequality Aversion and Voting on Redistribution," European Economic Review, 2012, 56 (7), $1406-1421$.

Huck, Steffen, "Responder Behavior in Ultimatum Offer Games with Incomplete Information," Journal of Economic Psychology, April 1999, 20 (2), 183-206.

Kamas, Linda and Anne Preston, "Distributive and Reciprocal Fairness: What can we Learn from the Heterogeneity of Social Preferences?," Journal of Economic Psychology, 2012, 33 (3), $538-553$.

Klempt, Charlotte and Kerstin Pull, "Generosity, Greed and Gambling: What Difference Does Asymmetric Information in Bargaining Make?," Jena Economic Research Papers, 2009. 
Konow, James, "Fair Shares: Accountability and Cognitive Dissonance in Allocation Decisions," American Economic Review, September 2000, 90 (4), 1072-1091.

Mitzkewitz, Michael and Rosemarie Nagel, "Experimental Results on Ultimatum Games with Incomplete Information," International Journal of Game Theory, June 1993, 22 (2), 171-198.

Rapoport, Amnon and James A Sundali, "Ultimatums in Two-Person Bargaining with One-Sided Uncertainty: Offer Games," International Journal of Game Theory, 1996, 25 (4), 475-94.

Rohde, Ingrid M. T. and Kirsten I. M. Rohde, "Risk Attitudes in a Social Context," Journal of Risk and Uncertainty, October 2011, 43 (3), 205-225.

Sauermann, Jan and André Kaiser, "Taking Others into Account: Self-Interest and Fairness in Majority Decision Making," American Journal of Political Science, 2010, $54(3), 667-685$.

Tyran, Jean-Robert and Rupert Sausgruber, "A Little Fairness may Induce a Lot of Redistribution in Democracy," European Economic Review, 2006, 50 (2), 469 - 485.

\section{A. Descriptive Statistics}


Table 3: Dictators' Transfer Decisions - Summary Statistics Baseline Sessions

\begin{tabular}{|c|c|c|c|}
\hline & Mean & Standard Deviation & Median \\
\hline \multicolumn{4}{|l|}{ 1st Part } \\
\hline Transfer $(=1)$ & .36 & .48 & 0 \\
\hline \multicolumn{4}{|l|}{ 2nd Part (with reward) } \\
\hline Transfer $(=1)$ & .4 & .5 & 0 \\
\hline \multicolumn{4}{|l|}{ 3rd Part (with reward) } \\
\hline Benefit $=25:$ Transfer $(=1)$ & .24 & .43 & 0 \\
\hline Benefit $=30:$ Transfer $(=1)$ & .22 & .42 & 0 \\
\hline Benefit $=40:$ Transfer $(=1)$ & .22 & .42 & 0 \\
\hline Benefit $=50:$ Transfer $(=1)$ & .27 & .45 & 0 \\
\hline Benefit $=60:$ Transfer $(=1)$ & .33 & .48 & 0 \\
\hline Benefit $=70$ : Transfer $(=1)$ & .33 & .48 & 0 \\
\hline \multicolumn{4}{|l|}{ 4th Part } \\
\hline Benefit $=25:$ Transfer $(=1)$ & .18 & .39 & 0 \\
\hline Benefit $=30:$ Transfer $(=1)$ & .18 & .37 & 0 \\
\hline Benefit $=40:$ Transfer $(=1)$ & .18 & .39 & 0 \\
\hline Benefit $=50:$ Transfer $(=1)$ & .24 & .43 & 0 \\
\hline Benefit $=60:$ Transfer $(=1)$ & .27 & .45 & 0 \\
\hline Benefit $=70:$ Transfer $(=1)$ & .31 & .47 & 0 \\
\hline$N=45$ & & & \\
\hline
\end{tabular}


Table 4: Dictators' Transfer Decisions - Summary Statistics Robustness Sessions

\begin{tabular}{|c|c|c|c|}
\hline & Mean & Standard Deviation & Median \\
\hline \multicolumn{4}{|l|}{ 4th Part } \\
\hline Transfer $(=1)$ & .23 & .43 & 0 \\
\hline \multicolumn{4}{|l|}{ 2nd Part (with reward) } \\
\hline Transfer $(=1)$ & .2 & .41 & 0 \\
\hline \multicolumn{4}{|l|}{ 3rd Part (with reward) } \\
\hline Benefit $=25:$ Transfer $(=1)$ & .27 & .45 & 0 \\
\hline Benefit $=30:$ Transfer $(=1)$ & .23 & .43 & 0 \\
\hline Benefit $=40:$ Transfer $(=1)$ & .2 & .41 & 0 \\
\hline Benefit $=50:$ Transfer $(=1)$ & .27 & .45 & 0 \\
\hline Benefit $=60$ : Transfer $(=1)$ & .27 & .45 & 0 \\
\hline Benefit $=70$ : Transfer $(=1)$ & .23 & .43 & 0 \\
\hline \multicolumn{4}{|l|}{ 1st Part } \\
\hline Benefit $=25:$ Transfer $(=1)$ & .23 & .43 & 0 \\
\hline Benefit $=30:$ Transfer $(=1)$ & .17 & .38 & 0 \\
\hline Benefit $=40:$ Transfer $(=1)$ & .1 & .31 & 0 \\
\hline Benefit $=50$ : Transfer $(=1)$ & .17 & .38 & 0 \\
\hline Benefit $=60:$ Transfer $(=1)$ & .17 & .38 & 0 \\
\hline Benefit $=70:$ Transfer $(=1)$ & .23 & .43 & 0 \\
\hline$N=30$ & & & \\
\hline
\end{tabular}




\section{B. Derivations}

In this section, we show under which parameters individuals are willing to transfer with efficiency concern, maximin preferences, and inequality aversion. We begin with decisions under symmetric information. Subsequently, we deal with the asymmetric information case.

\section{B.1. Symmetric Information}

\section{B.1.1. Efficiency Concern and Maximin Preferences}

Following Charness and Rabin (2002), the utility of an individual $i$ in the role of $A$ is

$$
U_{A}^{i}\left(\pi_{A}, \pi_{B}\right)=\left(1-\lambda^{i}\right) \pi_{A}+\lambda^{i}\left[\delta^{i} \cdot \min \left[\pi_{A}, \pi_{B}\right]+\left(1-\delta^{i}\right)\left(\pi_{A}+\pi_{B}\right)\right]
$$

where $\pi_{A}$ and $\pi_{B}$ are the monetary payoffs of $A$ and $B$, respectively. Parameter $\lambda^{i}=0$ corresponds to purely selfish preferences. For $0<\lambda^{i}<1, \delta^{i}=0$ means that prosocial behavior is only driven by an efficiency concern, i.e., a desire to maximize total payoffs, and $\delta^{i}=1$ means that prosocial behavior is only driven by maximin preferences, i.e., a desire to maximize both players' minimal payoff.

Applied to our setting, subject $i$ has to compare two levels of utility. The utility $U_{A}^{i}(100,50)$ if $i$ does not transfer:

$$
U_{A}^{i}(100,50)=\left(1-\lambda^{i}\right) 100+\lambda^{i}\left[\delta^{i} 50+\left(1-\delta^{i}\right)(100+50)\right]
$$

and for a given value of $b$ the utility $U_{A}^{i}(80,50+b)$ if $i$ transfers:

$$
U_{A}^{i}(80,50+b)=\left(1-\lambda^{i}\right) 80+\lambda^{i}\left[\delta^{i} \cdot \min [80,50+b]+\left(1-\delta^{i}\right)(80+50+b)\right]
$$


For the sake of exposition, we focus on two discrete cases. Subjects either have a pure efficiency concern $\left(\delta^{i}=0\right)$ or have pure maximin preferences $\left(\delta^{i}=1\right)$.

Efficiency Concern Given his individual parameter $\lambda^{i}$ and the value of $b$, player $i$ will transfer if

$$
U_{A}^{i}(80,50+b)>U_{A}^{i}(100,50) \Leftrightarrow \lambda^{i}>\frac{20}{b} .
$$

If $\lambda^{i}>\frac{4}{5}$, then individual $i$ will transfer for all values of $b$. For $\frac{2}{7}<\lambda^{i}<\frac{4}{5}$ let $b^{*}$ denote the lowest value of $b$ for which $i$ is willing to transfer. Note that $b^{*}$ is at least 70 . Individual $i$ will transfer for $b^{*}$ and all values of $b$ with $b>b^{*}$. If, however, $\lambda^{i}<\frac{2}{7}$ holds, then $i$ will never transfer. Hence, subjects with an efficiency concern should exhibit the following transfer pattern. Either they do not transfer at all, or they transfer for a particular value of $b^{*}$ and all values $b>b^{*}$.

Maximin Preferences Subjects with maximin preferences will transfer the 20 points if it holds that:

$$
\begin{array}{r}
U_{A}^{i}(80,50+b)>U_{A}^{i}(100,50) \\
\left(1-\lambda^{i}\right) 80+\lambda^{i} \min [80,50+b]>100-\lambda^{i} 50 \\
\lambda^{i}(\min [80,50+b]-30)>20 \\
\lambda^{i}>\frac{20}{(\min [80,50+b]-30)}
\end{array}
$$

If $\lambda^{i}>\frac{2}{5}, i$ will transfer to achieve a more equal allocation for values of $b>25$. If $\lambda^{i}>\frac{20}{45}, i$ will also transfer for $b=25$. If, however, $\lambda^{i}<\frac{2}{5}, i$ will not transfer as selfishness motives dominate. 


\section{B.1.2. Inequality Aversion}

In contrast to maximin preferences, the specification of Fehr and Schmidt (1999) can lead to behavior that is consistent with transfers for low values of $b$ but no transfers once the benefit level is above 50 .

The utility function by Fehr and Schmidt (1999) for the two-player case is as follows,

$$
U_{A}^{i}\left(\pi_{A}, \pi_{B}\right)=\pi_{A}-\alpha^{i} \max \left[0, \pi_{B}-\pi_{A}\right]-\beta^{i} \max \left[0, \pi_{A}-\pi_{B}\right]
$$

with the assumption that $\beta^{i} \leq \alpha^{i}$ and $0 \leq \beta^{i}<1$. To begin with, note that it holds that $U_{A}(80,80)>U_{A}(80,75)>U_{A}(80,90)>U_{A}(80,100)$ for all parameters as one can directly see from the following equations (and using that $\alpha^{i} \geq \beta^{i}$ ):

$$
\begin{array}{r}
U_{A}(80,80)=80 \\
U_{A}(80,75)=80-5 \beta^{i} \\
U_{A}(80,90)=80-10 \alpha^{i} \\
U_{A}(80,100)=80-20 \alpha^{i}
\end{array}
$$

Hence, whenever an individual is willing to transfer for $b=50$, he will be willing to transfer for values of $b<50$ as well. Next, we show that there actually exist parameters such that subjects may transfer for $b=50$. 


$$
\begin{array}{r}
U_{A}(80,100)>U_{A}(100,50) \\
80-20 \alpha^{i}>100-50 \beta^{i} \\
\beta^{i}>\frac{2}{3}
\end{array}
$$

For values of $b>50$, however, no parameters exist such that individuals will transfer. Suppose $U_{A}(80,110)>U_{A}(100,50)$ held, then

$$
\begin{array}{r}
U_{A}(80,110)>U_{A}(100,50) \\
80-30 \alpha^{i}>100-50 \beta^{i} \\
\beta^{i}>1
\end{array}
$$

Yet, by assumption $\beta^{i}<1$. Thus, for $b=60$ no admissible parameters exists, such that a transfer makes an individual better off.

\section{B.2. Asymmetric Information}

Efficiency Concern Individuals with a pure efficiency concern have a linear utility function. Hence, they are risk neutral and transfer under asymmetric information iff they transfer under $b=45$. Then, it holds that an individual $i$ who transfers for $b=40$ should transfer under asymmetric information. However, an individual who does not transfer for $b=50$, should not transfer under asymmetric information.

maximin Concern For maximin preferences, the hypotheses one can derive are simple as one can actually only observe three patterns. Subjects either transfer for no value of $b$, for all values of $b$, or they transfer for all values of $b$ larger than 25 . In the case 
that subjects do not transfer at all they should obviously not transfer under asymmetric information. Similarly, if subjects transfer for all values of $b$, obviously they should transfer under asymmetric information. If subjects only transfer for $b>25$, there exists a narrow parameter range of $\lambda$ such that they should not transfer under asymmetric information whereas otherwise they should. ${ }^{19}$ In our experiment, however, the last case practically does not play a role because we do not observe subjects who transfer for all values above $b>25$ but not for $b=25$.

Inequality Aversion We will proceed as follows. We will show it always holds that the utility from transferring under asymmetric information $E\left(U_{A}\left(\pi_{A}, \pi_{B}\right) \mid\right.$ transfer $\left.=Y E S\right)$ is smaller than the utility from transferring for $b=40$ but larger than for $b=50$ under symmetric information, that is, it holds that $U_{A}(80,90)>E\left(U_{A}\left(\pi_{A}, \pi_{B}\right) \mid\right.$ transfer $=$ $Y E S)>U_{A}(80,100)$. Hence, if it holds that player $i$ transfers for $b=50$, i.e., $U_{A}(80,100)>U_{A}(100,50)$, then it also holds that $E\left(U_{A}\left(\pi_{A}, \pi_{B}\right) \mid\right.$ transfer $\left.=Y E S\right)>$ $U_{A}(100,50)$. Thus, a transfer for $b=50$ then implies that a player should transfer under asymmetric information. On the other hand, if player $i$ does not transfer for $b=40$, i.e., $U_{A}(80,90)<U_{A}(100,50)$, it implies that $E\left(U_{A}\left(\pi_{A}, \pi_{B}\right) \mid\right.$ transfer $\left.=Y E S\right)<$ $U_{A}(100,50)$ and therefore a player will also not transfer under asymmetric information.

For $\alpha^{i}, \beta^{i}>0$ consider:

$$
\begin{array}{r}
U_{A}(80,90)-E\left(U_{A}\left(\pi_{A}, \pi_{B}\right) \mid \text { transfer }=Y E S\right)= \\
80-10 \alpha^{i}-\left(80-\frac{1}{6}\left[5 \beta^{i}+100 \alpha^{i}\right]\right)= \\
\frac{40}{6} \alpha^{i}+\frac{5}{6} \beta^{i}>0
\end{array}
$$

\footnotetext{
${ }^{19}$ More precisely, when $\frac{120}{300}<\lambda<\frac{120}{295}$. Then the utility from not transferring $(100-50 \lambda)$ is smaller than the utility from a transfer with $30,40,50,60$, or 70 (which is 80 ) but larger than the expected utility $80-\frac{5}{6} \lambda$.
} 
Figure 3: The Effect of Reward on Transfers

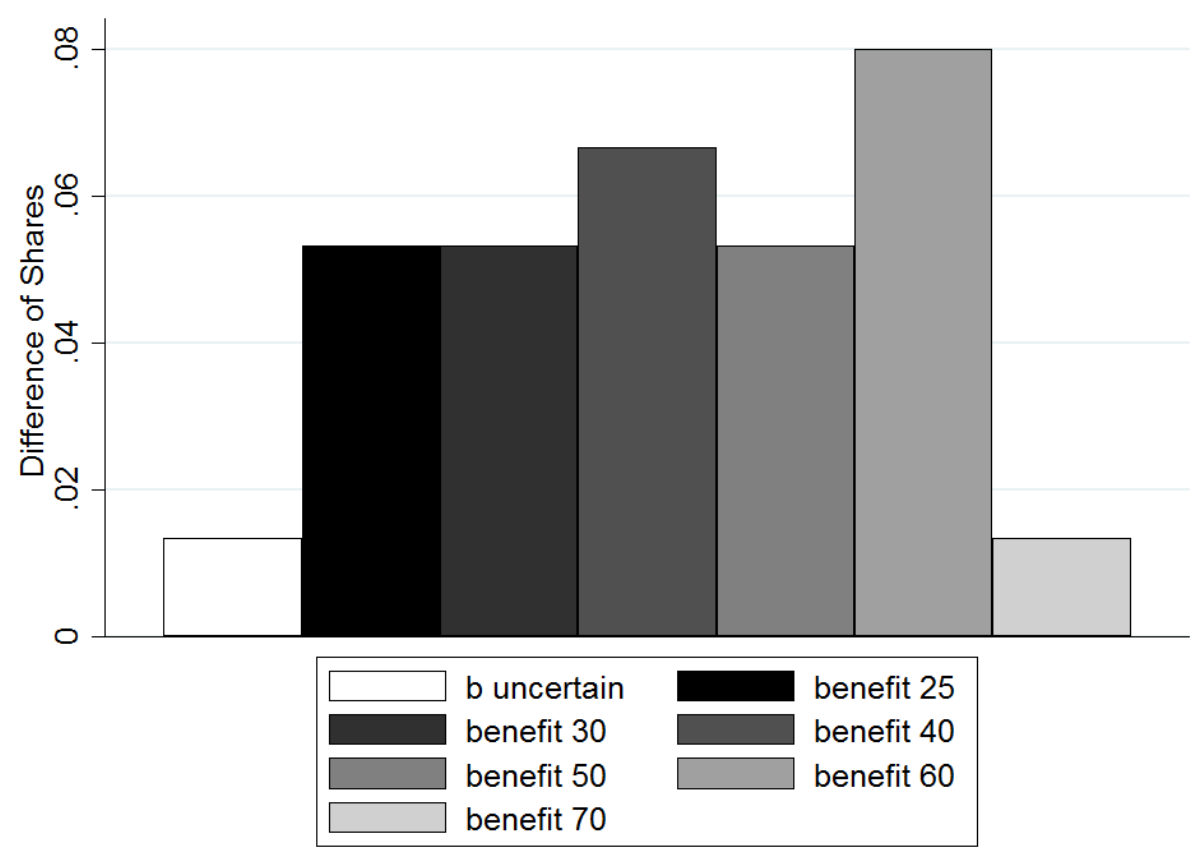

Notes: Bar 1 depicts the difference between the shares of individuals who transfer in part 2 and the share of individuals who transfer in part 1. Bars 2-7 depict the differences between the shares of individuals who transfer in part 3 and the share of individuals who transfer in part 4 for each level of benefit. $N=75$.

And lastly, as $\beta^{i} \leq \alpha^{i}$ :

$$
\begin{array}{r}
E\left(U_{A}\left(\pi_{A}, \pi_{B}\right) \mid \text { transfer }=Y E S\right)-U_{A}(80,100)= \\
80-\frac{1}{6}\left[5 \beta^{i}+100 \alpha^{i}\right]-\left[80-20 \alpha^{i}\right]= \\
-\frac{5}{6} \beta^{i}+\frac{20}{6} \alpha^{i}>0
\end{array}
$$

\section{Additional Tables and Graphs}

\section{C.1. Effect of Reward}


Table 5: Dictators' Transfer Decision - Reward

\begin{tabular}{lc}
\hline \hline & $(1)$ \\
\hline Transfer when benefit $=25(=1)$ & $-0.0867^{* *}$ \\
& $(0.0430)$ \\
Transfer when benefit $=30(=1)$ & $-0.113^{* * *}$ \\
& $(0.0388)$ \\
Transfer when benefit $=40(=1)$ & $-0.133^{* * *}$ \\
& $(0.0334)$ \\
Transfer when benefit $=50(=1)$ & $-0.0733^{*}$ \\
& $(0.0401)$ \\
Transfer when benefit $=60(=1)$ & -0.0467 \\
& $(0.0406)$ \\
Transfer when benefit $=70(=1)$ & -0.0267 \\
& $(0.0446)$ \\
Reward $(=1)$ & $0.0476^{* *}$ \\
& $(0.0197)$ \\
\hline$N$ & $0.290^{* * *}$ \\
\hline \hline
\end{tabular}

Notes: Standard errors are in parentheses. Table reports results from an OLS regression. Dependent variable is the individual transfer decision. Explanatory variables are the benefit levels under symmetric information. The omitted category is the asymmetric information case. Standard errors are clustered at the subject level.

Level of significance: ${ }^{*} \mathrm{p}<0.10,{ }^{* *} \mathrm{p}<0.05,{ }^{* * *} \mathrm{p}<0.01$ 
C.2. Robustness of Sequence 
Figure 4: Percentage of Transfers - Baseline versus Robustness Sessions

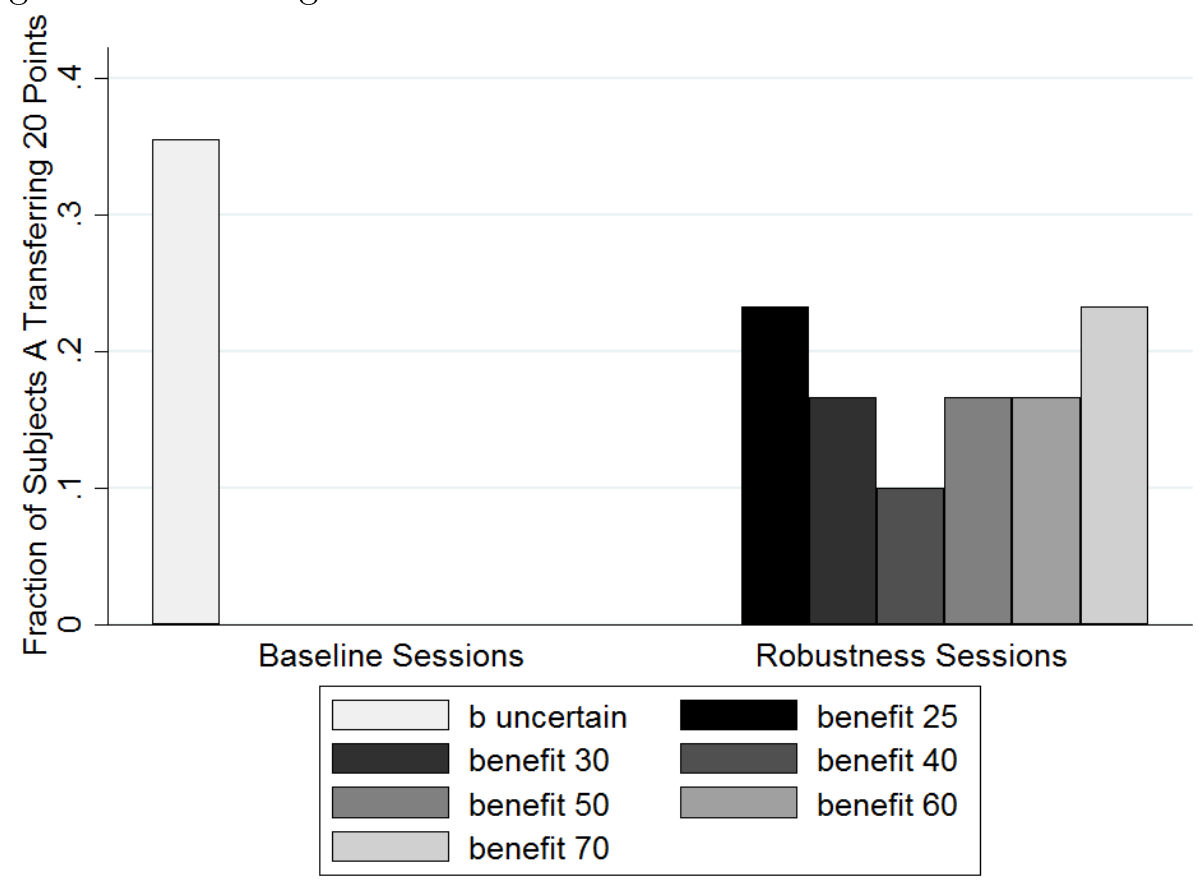

Notes: The figure depicts the share of individuals in the role of $A$ who transfer in the baseline sessions and in the robustness sessions in the first part. The first bar refers to transfers under asymmetric information (baseline sessions). Bars 2-7 depict transfers for each level of benefit under symmetric information (robustness sessions). 
Figure 5: Percentage of Transfers - Baseline versus Robustness Sessions

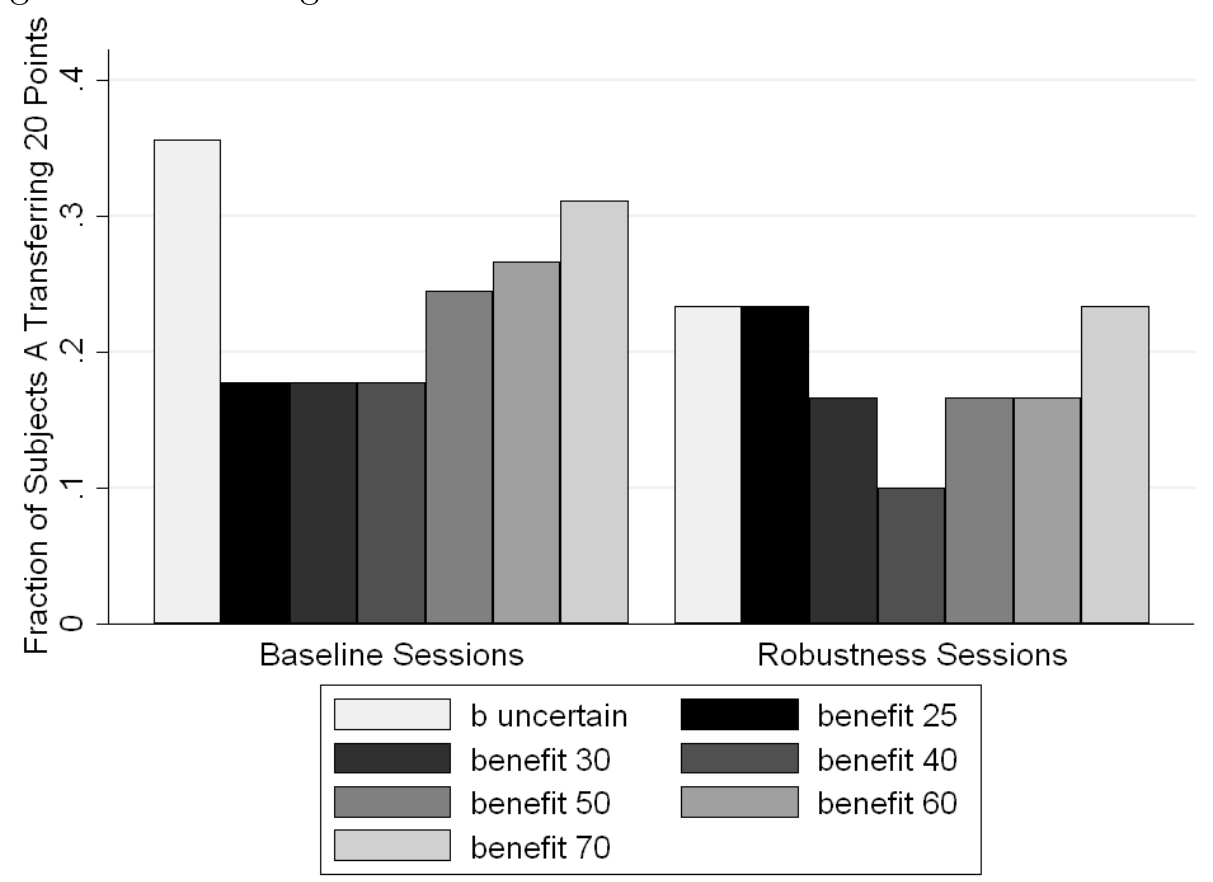

Notes: The figure depicts the share of individuals in the role of A who transfer for the baseline sessions and the robustness sessions. The first bar refers to transfers under asymmetric information. Bars 2-7 depict transfers for each level of benefit under symmetric information. 
Figure 6: The Effect of Reward on Transfers - Baseline Sessions versus Robustness Sessions

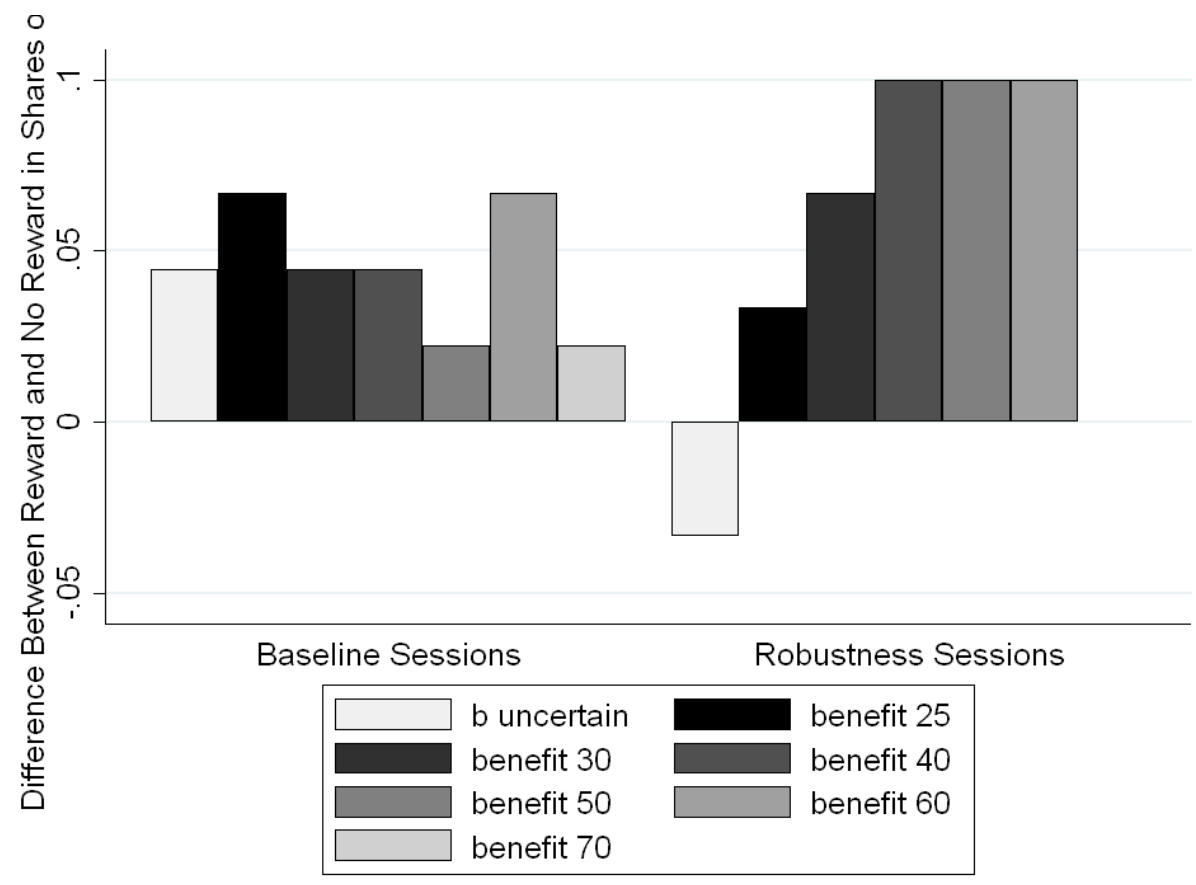

Notes: Bar 1 depicts the difference between the shares of individuals who transfer with reward and the share of individuals who transfer without reward under asymmetric information. Bars 2-7 depict the difference between the shares of individuals who transfer with reward and the share of individuals who transfer without reward for each level of benefit under symmetric information. 


\section{Instructions}

The original instructions were in German. In the following, we provide an English version. 


\section{General Instructions for Participants}

You are now participating in an economic experiment. Please, read the following instruction carefully. It explains everything what you need to know for the participation in the experiment. If you have any question, please, just raise your hand. Your question will be answered at your workplace. Apart from that, any sort of communication during the experiment is forbidden. If you violate this rule, you will be excluded from the experiment and will not receive any payment.

The experiment consists of four parts. You obtain a separate instruction for each part.

In all four parts you can earn points. It holds that:

10 Points = 1 Euro

Your final payment will be determined by the payment earned in one out of the four parts comprising the experiment. At the end of the experiment, the experimenter draws from an urn. The draw will determine one out of the four parts for all participants. You will receive the payment which you earned for this part in cash.

After each part you will be informed how many points you earned for this part. You obtain no information concerning the earnings of other participants.

\section{The Experiment}

The computer randomly assigns either the role of Participant A or Participant B to each participant. At the beginning of the experiment, your computer will inform you whether you are Participant A or Participant B.

This assignment does not change during the experiment. Each participant will stay either Participant A or Participant B during all four parts of the experiment.

In all four parts two participants, A and B, are randomly assigned to each other.

In each part of the experiment, another Participant B is assigned to a participant A. As a result, the same two participants will never be assigned to each other more than once.

No participant knows whom he is assigned to. That means all decisions are anonymous.

Do you have any questions? If yes, please raise your hand. The experimenter will answer your question at your workplace.

Please, read the instruction for part 1 of the experiment on the next pages. 
You obtain the instructions for parts 2 to 4 at the beginning of the respective part. 


\section{Part 1}

Participant A obtains an amount of 100 points. Participant $\mathbf{B}$ obtains an amount of 50 points.

\section{The Decision of Participant A}

$\mathbf{A}$ has to decide if he is ready to spend 20 points in order to increase the payment of $\mathbf{B}$ by $\mathbf{b}$ points. That means instead of the amount of 50 points $\mathbf{B}$ obtains the payoff of $\mathbf{5 0}+\mathbf{b}$. A can spend either 20 points or nothing.

If $\mathbf{A}$ decides not to spend 20 points, both participants obtain their original payoffs: A receives 100 and $\mathbf{B} 50$ points.

The exact value of $\mathbf{b}$ is determined before the start of the actual experiment: the experimenter draws one ball from an urn.

The urn contains the following balls, each represents one value of $\mathbf{b}$ :

\section{1 ball with $b=25,1$ ball with $b=30,1$ ball with $b=40$,}

$$
1 \text { ball with } b=50,1 \text { ball with } b=60,1 \text { ball with } b=70
$$

Participant $\mathbf{B}$ will be informed on his screen which ball has been drawn. Participant $\mathbf{A}$ however, will not be informed about the exact value of $\mathbf{b}$.

\section{The Decision of Participant B}

In contrast to Participant $\mathbf{A}$, Participant $\mathbf{B}$ is informed about the exact value of $\mathbf{b}$ at the beginning of part 1 .

Participant B makes no decisions. 
Please, answer the following control questions. These question do not influence your payments and only serve to check if all participants understood the rules of the experiment correctly.

Question 1. Assume that Participant A decides to spend 20 points. What will be the payoffs if the ball with $b=30$ is drawn?

Payoff for A:

Payoff for B:

Question 2. Assume that Participant A decides not to spend 20 points. What will be the payoffs if the ball with $b=50$ is drawn?

Payoff for A:

Payoff for B:

After you have answered the questions, please, raise your hand. The experimenter will check your answers at your workplace. When all the participants are ready, we start with the actual experiment. 


\section{Part 2}

Participant A obtains an amount of 100 points. Participant $\mathbf{B}$ obtains an amount of 50 points.

\section{The Decision of Participant A}

A has to decide if he is ready to spend 20 points in order to increase the payment of $\mathbf{B}$ by $\mathbf{b}$ points. That means instead of the amount of 50 points $\mathbf{B}$ obtains the payoff of $50+\mathrm{b}$. A can spend either 20 points or nothing.

If $\mathbf{A}$ decides not to spend 20 points, both participants obtain their original payoffs: A receives 100 and $\mathbf{B} 50$ points.

The exact value of $\mathbf{b}$ is determined before the start of the actual experiment: the experimenter draws one ball from an urn.

The urn contains the following balls, each represents one value of $\mathbf{b}$ :

\section{1 ball with $b=25,1$ ball with $b=30,1$ ball with $b=40$,}

\section{1 ball with $b=50,1$ ball with $b=60,1$ ball with $b=70$}

Participant $\mathbf{B}$ will be informed on his screen which ball has been drawn. Participant $\mathbf{A}$ however, will not be informed about the exact value of $\mathbf{b}$.

If $\mathbf{A}$ decides to spend 20 points, he obtains a reward - $\mathbf{r}$ points. It holds that $\mathbf{5}$ points $\leq \mathbf{r} \leq \mathbf{1 0}$ points. The exact value of $\mathbf{r}$ will be determined after $\mathbf{b}$ is determined. Participant $\mathbf{A}$ will be informed about the value of $\mathbf{r}$ on his display.

\section{The Decision of Participant B}

In contrast to Participant $\mathbf{A}$, Participant $\mathbf{B}$ is informed about the exact value of $\mathbf{b}$ at the beginning of part 1. Participant $\mathbf{B}$ will be informed about the value of $\mathbf{r}$ on his display.

Participant $\mathbf{B}$ makes no decisions. 


\section{Part 3}

Participant A obtains an amount of 100 points. Participant $\mathbf{B}$ obtains an amount of 50 points.

\section{The Decision of Participant A}

$\mathbf{A}$ has to decide if he is ready to spend 20 points in order to increase the payment of $\mathbf{B}$ by $\mathbf{b}$ points. That means instead of the amount of 50 points $\mathbf{B}$ obtains the payoff of $50+\mathbf{b}$. A can spend either 20 points or nothing.

If $\mathbf{A}$ decides not to spend 20 points, both participants obtain their original payoffs: $\mathbf{A}$ receives 100 and $\mathbf{B} 50$ points.

b can obtain different values. A has to make a decision for each of the following cases:

\section{1. $b=25$}

2. $\mathbf{b}=\mathbf{3 0}$

3. $b=40$

4. $b=50$

5. $b=60$

6. $b=70$

In the end of part 3, the experimentator draws one ball from the urn, which will determine the decision problem, relevant for the payoff in this part of the experiment.

If $\mathbf{A}$ decides to spend 20 points, he obtains a reward - $\mathbf{r}$ points. It holds that $\mathbf{5}$ points $\leq \mathbf{r} \leq \mathbf{1 0}$ points. Participant $\mathbf{A}$ will be informed about the value of $\mathbf{r}$ on his display.

\section{The Decision of Participant B}

Participant $\mathbf{B}$ makes no decisions. Participant $\mathbf{B}$ will be informed about the value of $\mathbf{r}$ on his display. 
Please, answer the following control questions. These question do not influence your payments and only serve to check if all participants understood the rules of the experiment correctly.

Question 1. Assume that Participant A decides to spend 20 points. What will be the payoffs in the case (1)?

Payoff for A:
Payoff for B:

Question 2. Assume that Participant A decides not to spend 20 points. What will be the payoffs in the case (4)?

Payoff for A:

Payoff for B:

After you have answered the questions, please, raise your hand. The experimenter will check your answers at your workplace. 


\section{Part 4}

Participant A obtains an amount of 100 points. Participant $\mathbf{B}$ obtains an amount of 50 points.

\section{The Decision of Participant A}

$\mathbf{A}$ has to decide if he is ready to spend 20 points in order to increase the payment of $\mathbf{B}$ by $\mathbf{b}$ points. That means instead of the amount of 50 points $\mathbf{B}$ obtains the payoff of $\mathbf{5 0}+\mathbf{b}$. A can spend either 20 points or nothing.

If $\mathbf{A}$ decides not to spend 20 points, both participants obtain their original payoffs: $\mathbf{A}$ receives 100 and $\mathbf{B} 50$ points.

b can obtain different values. A has to make a decision for each of the following cases:

1. $\mathbf{b}=\mathbf{2 5}$

2. $\mathbf{b}=\mathbf{3 0}$

3. $\mathbf{b}=\mathbf{4 0}$

4. $\mathbf{b}=\mathbf{5 0}$

5. $b=60$

6. $\mathbf{b}=\mathbf{7 0}$

In the end of part 3, the experimentator draws one ball from the urn, which will determine the decision problem, relevant for the payoff in this part of the experiment.

\section{The Decision of Participant B}

Participant $\mathbf{B}$ makes no decisions. 